\title{
MicroRNA-17-5p inhibits proliferation and triggers apoptosis in non-small cell lung cancer by targeting transforming growth factor $\beta$ receptor 2
}

\author{
HUI LI ${ }^{1,2}$, HUI ZHOU ${ }^{3,4}$, JIASHUN LUO ${ }^{5}$ and JUN HUANG ${ }^{6}$
}

${ }^{1}$ Institute of Medical Examination; ${ }^{2}$ Department of Microbiology and Immunology, Medical School of Jishou University, Jishou, Hunan 416000; ${ }^{3}$ Department of Medical Oncology, Tumor Hospital of Hunan Province, Changsha, Hunan 410000;

${ }^{4}$ State Key Laboratory of Medical Genetics, Central South University, Changsha, Hunan 410078;

${ }^{5}$ Institute of Medical Research, Medical School of Jishou University, Jishou, Hunan 416000; ${ }^{6}$ Department of Orthopaedics, Second Xiangya Hospital of Central South University, Changsha, Hunan 410011, P.R. China

Received September 16, 2015; Accepted January 20, 2017

DOI: $10.3892 / \mathrm{etm} .2017 .4347$

\begin{abstract}
MicroRNAs (miRs) are small non-coding RNAs that suppress gene expression by directly binding to the 3'-untranslated region of their target mRNAs. Specific miRs serve key roles in the development and progression of non-small cell lung cancer (NSCLC). The aim of the present study was to determine the mechanism of miR-17-5p in the regulation of NSCLC cell survival and proliferation. Reverse transcription-quantitative polymerase chain reaction data indicated that miR-17-5p was significantly downregulated in 28 NSCLC tissues compared with 7 non-tumorous lung tissues. Furthermore, lower miR-17-5p expression was associated with a higher pathological stage in NSCLC patients. Lower miR-17-5p expression was also observed in several common NSCLC cell lines, including SK-MES-1, A549, SPCA-1, H460, H1229 and HCC827, compared with the bronchial epithelium cell line, BEAS-2B. Additionally, overexpression of miR-17-5p significantly inhibited proliferation while inducing the apoptosis of NSCLC H460 cells. Subsequently, transforming growth factor $\beta$ receptor 2 (TGF $\beta$ R2) was identified as a direct target of miR-17-5p using a luciferase reporter assay. Western blot analysis confirmed that miR-17-5p negatively mediated the expression of TGF $\beta$ R 2 in NSCLC cells. Furthermore, small interfering RNA-induced downregulation of TGF $\beta \mathrm{R} 2$ also suppressed the proliferation of $\mathrm{H} 460$ cells while triggering apoptosis. Therefore, the results of the current study suggest that miR-17-5p may inhibit proliferation and trigger apoptosis in NSCLC H460 cells at least partially by targeting TGF $\beta$ R2.
\end{abstract}

Correspondence to: Dr Jun Huang, Department of Orthopaedics, Second Xiangya Hospital of Central South University, 139 Middle Renmin Road, Changsha, Hunan 410011, P.R. China

E-mail: huangjundoctor@163.com

Key words: non-small cell lung cancer, microRNA-17-5p, transforming growth factor $\beta$ receptor 2 , proliferation, apoptosis

\section{Introduction}

Lung cancer is the leading cause of cancer-associated mortality worldwide (1) and non-small cell lung cancer (NSCLC) accounts for $\sim 80 \%$ of all lung cancer cases $(1,2)$. Despite improvements in the combination of surgical resection, radiotherapy and chemotherapy to treat patients NSCLC, the prognosis of NSCLC patients following curative therapy remains poor $(1,3)$. Therefore, the development of novel therapeutic targets is urgently required for the treatment of NSCLC.

MicroRNAs (miRs), a class of non-coding small RNA consisting of 22-25 nucleotides, generally act as negative regulators of gene expression (4-6). Deregulation of miRs has been implicated in various human malignancies, including NSCLC (7-9). Additionally, it has been demonstrated that certain miRs can directly regulate the expression of key tumor suppressors or oncogenes, therefore, they are important in the tumorigenesis and malignant progression of human cancer $(10,11)$. To date, the targets of numerous miRs remain unclear and verification of these target genes is important to allow the development of effective therapeutic strategies to treat cancer.

miR-17-5p is an important member of the miR-17-92 cluster (12). A normal miR-17-92 cluster is necessary for normal lung development and alterations in its expression have been reported in various pulmonary diseases, such as lung cancer $(13,14)$. Heegaard et al $(15)$ demonstrated that the serum levels of miR-17-5p were significantly reduced in 220 cases of NSCLC tissues compared with matched normal tissue. Additionally, it was reported that downregulation of miR-17-5p contributed to the paclitaxel resistance of NSCLC A549 cells through overexpression of becline1 (16). The results of these previous studies suggest that miR-17-5p is a tumor suppressor in NSCLC. However, the exact role of miR-17-5p in the survival and proliferation of NSCLC cells remains unknown.

Transforming growth factor $\beta$ receptor 2 (TGF $\beta R 2)$ is a transmembrane protein that belongs to the serine/threonine protein kinase family and the TGF $\beta$ receptor subfamily (17). 
It can form a heterodimeric complex with another receptor protein and binds TGF $\beta$ to form a complex and phosphorylate proteins. These proteins then enter the nucleus and regulate the transcription of several cell proliferation-related genes (18). Increased expression of TGF $\beta$ R 2 was found to be associated with a poor clinical outcome of NSCLC patients treated with chemotherapy (19). Additionally, miR-34a was found to inhibit proliferation and promote the apoptosis of NSCLC H1299 cells by targeting TGF $\beta$ R2 (19). These results suggest that TGF $\beta$ R 2 acts as an oncogene in NSCLC.

Recently, TGF $\beta$ R2 was found to be a direct target gene of miR-93, which is a paralogue miR of the miR-17-92 cluster (17). Furthermore, the miR-17-92 cluster was found to reverse cisplatin resistance and inhibit metastasis in NSCLC by targeting TGF $\beta$ R2 (20). However, to the best of our knowledge, there have been no studies investigating whether TGF $\beta$ R2 is involved in miR-17-5p-mediated NSCLC cell survival and proliferation. Therefore, the present study aimed to reveal the mechanism of miR-17-5p in the regulation of NSCLC cell survival and proliferation.

\section{Materials and methods}

Tissue collection and ethics statement. Human NSCLC tissues $(n=28)$ and adjacent non-tumorous lung tissues $(n=7)$ were obtained from NSCLC patients admitted to the Tumor Hospital of Hunan Province (Changsha, China) between March 2010 and September 2011. These 28 NSCLC patients included 20 males and 8 females, with a mean age of 62 years; 12 were at T1 stage while 16 were at T2-T4 stage (21). The current study was approved by the Ethics Committee of Hunan Province (Hunan, China). Written informed consent was obtained from all participants. Histomorphology was confirmed using hematoxylin and eosin staining by the Department of Pathology, Tumor Hospital of Hunan Province. Tissues were then immediately snap-frozen in liquid nitrogen following surgical removal and stored at $-80^{\circ} \mathrm{C}$.

Cell culture. NSCLC cell lines (SK-MES-1, A549, SPCA-1, H460, H1229 and HCC827) and the non-tumorous human bronchial epithelium cell line BEAS-2B, were all obtained from the Cell Bank, China Academy of Sciences (Shanghai, China). All cell lines were cultured in RPMI-1640 medium (Life Technologies; Thermo Fisher Scientific, Inc., Waltham, MA, USA) supplemented with $10 \%$ fetal bovine serum (Life Technologies; Thermo Fisher Scientific, Inc.) at $37^{\circ} \mathrm{C}$ in $5 \%$ $\mathrm{CO}_{2}$.

Reverse transcription-quantitative polymerase chain reaction $(R T-q P C R)$. Total RNA was extracted from the tissues or cells using TRIzol (Sigma-Aldrich, Merck KGaA, Darmstadt, Germany) according to the manufacturer's instructions. qPCR was used to examine the relative miR-17-5p expression using a mirVana ${ }^{\mathrm{TM}}$ qRT-PCR microRNA detection kit (Life Technologies; Thermo Fisher Scientific, Inc.), according to the manufacturer's instructions and U6 was used as an internal reference. The specific primers for miR-17-5p and U6 were purchased from Genecopoeia, Inc., (Guangzhou, China). Primer sequences were not available. mRNA expression was detected using the standard SYBR-Green RT-PCR kit
(Takara Bio, Inc., Otsu, Japan) according to the manufacturer's instructions and glyceraldehyde 3-phosphate dehydrogenase (GAPDH) was used as an internal reference. The specific primers for TGF $\beta R 2$ were as follows: Forward, 5'-AAGATG ACCGCTCTGACATCA-3' and reverse, 5'-CTTATAGAC CTCAGCAAAGCGAC-3'. The specific primers for GAPDH were as follows: Forward, 5'-CAGCCACCCGAGATTGAG CA-3' and reverse, 5'-TAGTAGCGACGGGCGGTGTG-3'. The reaction conditions were $95^{\circ} \mathrm{C}$ for 3 min and 45 cycles of denaturation at $95^{\circ} \mathrm{C}$ for $15 \mathrm{sec}$ followed by an annealing/elongation step at $58^{\circ} \mathrm{C}$ for $30 \mathrm{sec}$. Fold-change was calculated using the relative quantification $\left(2^{-\Delta \Delta \mathrm{Cq}}\right)$ method (22).

Construction of recombinant vectors for luciferase reporter assay. The predicted miR-17-5p binding sites on the 3'-untranslated region (3'UTR) of TGF $\beta$ R2 were cloned into the pGL3 vector (Promega Corporation, Madison, WI, USA) named pGL3-TGFßR2-3'UTR. The mutant miR-17-5p binding sites on the 3'UTR of TGF $\beta$ R2 were constructed using a QuikChange Site-Directed Mutagenesis kit (Stratagene; Agilent Technologies, Inc., Santa Clara, CA, USA), in accordance with the manufacture's protocol. TGF $\beta$ R2 was also inserted into the pGL3 vector and named pGL3-TGF $\beta R 2$-mut-3'UTR.

Cell transfection. $\mathrm{H} 460$ cells $\left(5 \times 10^{5}\right.$ cells per well) were seeded in a 6-well plate with RPMI-1640 medium and incubated at $37^{\circ} \mathrm{C}$ overnight to $60-70 \%$ confluence. For miR-17-5p overexpression or knockdown, miR-17-5p mimic or inhibitor (Genecopoeia, Inc.) was diluted in serum-free Opti-minimal essential medium (MEM) and transfected with Lipofectamine ${ }^{\circledR} 2000$ (both Thermo Fisher Scientific, Inc.) in accordance with the manufacturer's instructions. For TGF $\beta$ R2 silencing, the NC small interfering (siRNA) (forward: 5'-UUCUCCGAACGU GUCACGUTT-3' and reverse: 5'-ACGUGACACGUUCGG AGAATT-3') and TGF $\beta R 2$-specific siRNA (forward: 5'-GAC CUCAAGAGCUCCAAUATT-3' and reverse: 5'-UAUUGG AGCUCUUGAGGUCTT-3') were purchased from Amspring (Changsha, China), diluted in serum-free Opti-MEM and transfected with Lipofectamine ${ }^{\circledR} 2000$. Levels of miR-17-5p and TGF 3 R2 expression were examined $48 \mathrm{~h}$ after transfection. For the luciferase reporter assay, H460 cells $\left(1 \times 10^{5}\right.$ cells per well) in 24-well plates were co-transfected with $500 \mathrm{ng}$ pGL3-TGF $\beta R 2-3$ 'UTR or pGL3-TGF $\beta R 2-m u t-3 ' U T R$, and $50 \mathrm{nM}$ miR-17-5p mimic or miR-negative control (miR-NC). Additionally, pRL-SV40 (Promega Corporation) was co-transfected as the control. Reporter assays were performed at $48 \mathrm{~h}$ after transfection using a Dual-Luciferase ${ }^{\circledR}$ assay system (Promega Corporation).

Cell proliferation detection. An MTT assay was used to examine cell proliferation. $\mathrm{H} 460$ cells $\left(5 \times 10^{4}\right.$ per well) were plated into a 96 -well plate and cultured at $37^{\circ} \mathrm{C}$ with $5 \% \mathrm{CO}_{2}$ for $12,24,48$ or $72 \mathrm{~h}$. Subsequently, $20 \mu \mathrm{l}$ MTT $(5 \mathrm{mg} / \mathrm{ml}$, Life Technologies; Thermo Fisher Scientific, Inc.) was added. Following incubation at $37^{\circ} \mathrm{C}$ for $4 \mathrm{~h}, 150 \mu \mathrm{l}$ dimethyl sulfoxide was added. The control was treated with dimethyl sulfoxide without MTT. Following incubation at room temperature for $10 \mathrm{~min}$, formazan production was detected by determining the optical density at $570 \mathrm{~nm}$ using a Multiskan FC enzyme immunoassay analyzer (Thermo Fisher Scientific, Inc.). 

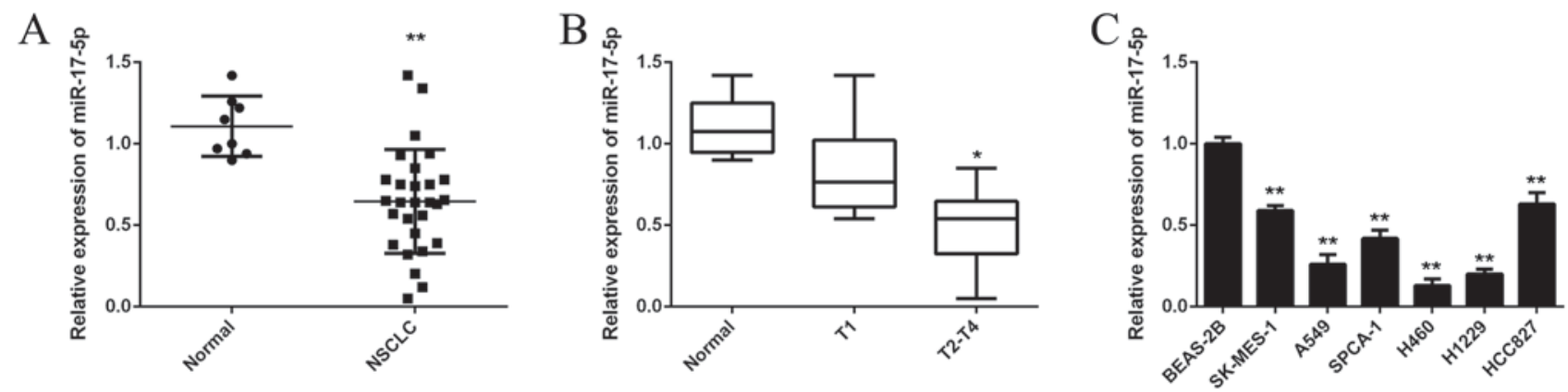

Figure 1. (A) qPCR determined levels of miR-17-5p expression in normal lung $(\mathrm{n}=7)$ and NSCLC $(\mathrm{n}=28)$ tissues. ${ }^{* *} \mathrm{P}<0.01$ vs. normal. (B) Decreased expression of miR-17-5p was associated with a higher pathological stage (T2-T4) of NSCLC. "P<0.05 vs. T1. (C) qPCR measured miR-17-5p expression in the human NSCLC cell lines SK-MES-1, A549, SPCA-1, H460, H1229 and HCC827, and the non-tumorous human bronchial epithelium cell line BEAS-2B. ${ }^{* *} \mathrm{P}<0.01$ vs. BEAS-2B. qPCR, quantitative polymerase chain reaction; NSCLC, non-small cell lung cancer; miR, microRNA.

Cell apoptosis assay. Cell apoptosis was examined using the Annexin V-fluorescein isothiocyanate (FITC) apoptosis detection kit (556547; BD Pharmingen, San Diego, CA, USA) according to the manufacturer's instructions. H460 cells were re-suspended in 1X binding buffer solution (BD Pharmingen) with Annexin V-FITC and propidium iodide (PI) and incubated for $15 \mathrm{~min}$ at room temperature in the dark. Apoptotic cells were analyzed using a BD Accuri C6 flow cytometer (BD Biosciences, Franklin Lakes, NJ, USA) with BD Accuri C6 software 1.0 (BD Biosciences).

Western blot analysis. Cells were lysed in cold radioimmunoprecipitation assay buffer (Sigma-Aldrich, Merck $\mathrm{KGaA}$ ). The protein concentration was determined using the bicinchoninic acid protein assay kit (Pierce Biotechnology, Inc., Thermo Fisher Scientific, Inc.). Protein was separated with $10 \%$ SDS-PAGE, transferred to a polyvinylidene difluoride (PVDF) membrane (Life Technologies; Thermo Fisher Scientific, Inc.). The membrane was then blocked in 5\% powdered milk dissolved in PBS (Life Technologies; Thermo Fisher Scientific, Inc.) containing 0.1\% Tween-20 (Sigma-Aldrich, Inc., Merck KGaA) at room temperature for $3 \mathrm{~h}$. Subsequently, the PVDF membrane was incubated with mouse anti-human monoclonal TGF $\beta$ R2 (1:200; ab78419; Abcam, Cambridge, MA, USA) or mouse anti-human GAPDH (1:200; ab8245; Abcam) primary antibodies for $3 \mathrm{~h}$ at room temperature, and then washed with Dulbecco's phosphate-buffered saline for $10 \mathrm{~min}$. The PVDF membrane was then incubated with rabbit anti-mouse secondary antibody $(1: 5,000 ;$ ab175743; Abcam) at room temperature for $1 \mathrm{~h}$. An enhanced chemiluminescence western blotting kit (Pierce Biotechnology, Inc.; Thermo Fisher Scientific, Inc.) was used to detect the protein bands according to the manufacturer's protocols. Protein bands were quantified by densitometric analysis using Image Lab analysis software 2.1 (Bio-Rad Laboratories, Inc., Hercules, CA, USA) and expressed as the density ratio vs. GAPDH.

Statistical methods. Results were expressed as the group means \pm standard error of the mean and analyzed using Student's t-test for two-group comparisons and one-way analysis of variance for multiple-group comparisons. SPSS 17.0 software (SPSS, Inc., Chicago, IL, USA) was used for the analysis. $\mathrm{P}<0.05$ was considered to indicate a statistically significant difference.

\section{Results}

miR-17-5p is downregulated in NSCLC tissues and cell lines. To determine the role of miR-17-5p in NSCLC, the expression of miR-17-5p was examined in 28 NSCLC tissues and 7 non-tumorous lung tissues using qPCR. The results showed that miR-17-5p was significantly downregulated in NSCLC tissues compared with non-tumorous lung tissues $(\mathrm{P}<0.01$; Fig. 1A). Additionally, miR-17-5p levels were significantly lower in T2-T4 stage NSCLC tissues compared with $\mathrm{T} 1$ stage NSCLC tissues $(\mathrm{P}<0.05$; Fig. $1 \mathrm{~B})$, suggesting that low miR-17-5p levels were associated with an advanced pathological stage of NSCLC. A significant downregulation of miR-17-5p in all NSCLC cell lines was also observed compared with non-tumorous bronchial epithelium BEAS-2B cells $(\mathrm{P}<0.01$; Fig. 1C). H460 cells exhibited the greatest downregulation of miR-17-5p (Fig. 1C), thus this cell line was used for all subsequent experiments.

miR-17-5p inhibits proliferation while triggering apoptosis in NSCLC H460 cells. H460 cells were transfected with miR-NC, miR-17-5p mimic or miR-17-5p inhibitor. At $48 \mathrm{~h}$ after transfection, qPCR was conducted to examine miR-17-5p expression. Transfection with miR-17-5p mimic was found to significantly increase miR-17-5p expression $(\mathrm{P}<0.01)$, while transfection with miR-17-5p inhibitor significantly decreased miR-17-5p expression $(\mathrm{P}<0.01)$ compared with the control group (Fig. 2A). The effects of miR-17-5p overexpression or downregulation on $\mathrm{H} 460$ cell proliferation were further studied by performing an MTT assay. The data showed that the absorbance in miR-17-5p-overexpressing $\mathrm{H} 460$ cells was significantly lower than in the control group ( $\mathrm{P}<0.01$; Fig. $2 \mathrm{~B})$. On the contrary, knockdown of miR-17-5p led to a significant upregulation of $\mathrm{H} 460$ cell proliferation compared with the control group $(\mathrm{P}<0.01$; Fig. $2 \mathrm{~B})$. These results indicated that miR-17-5p has a role in suppressing role in regulating $\mathrm{H} 460$ cell proliferation.

Furthermore, the apoptotic levels were examined further as apoptosis may be a direct cause of proliferation inhibition. H460 cells were stained with Annexin V-conjugated FITC 
A

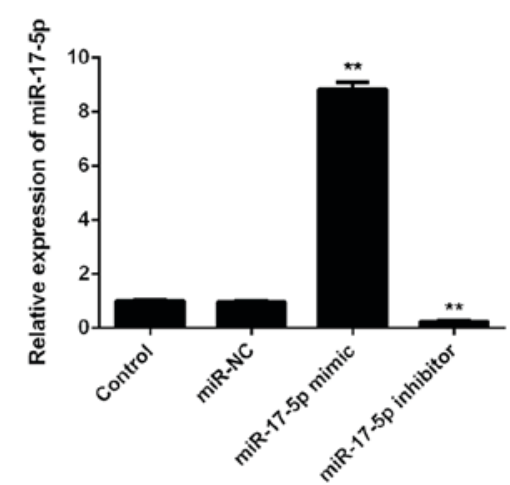

B

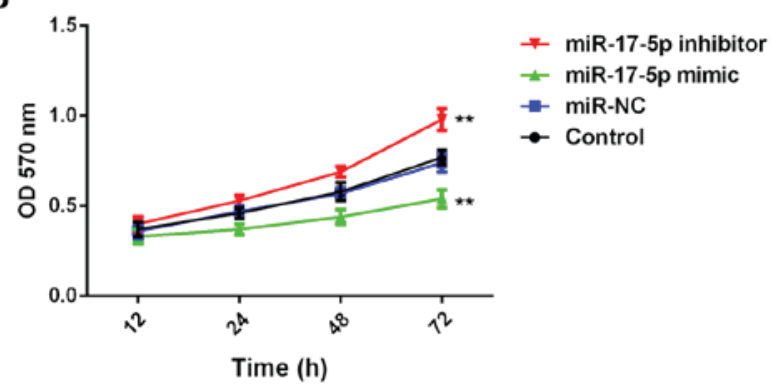

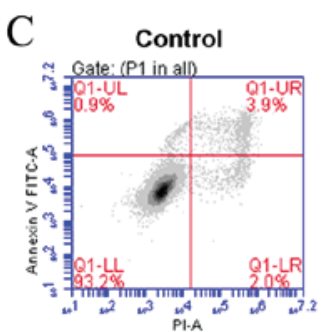

miR-17-5p mimic

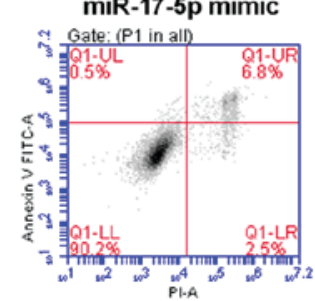

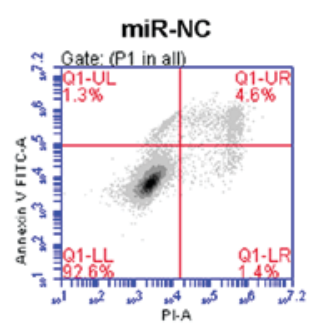

miR-17-5p inhibitor

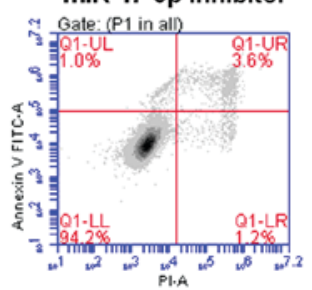

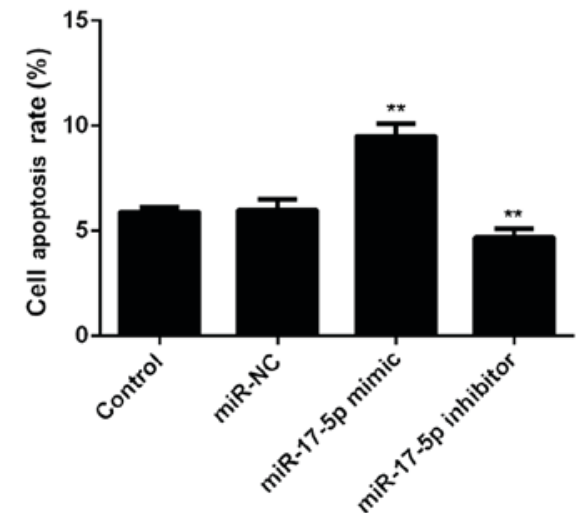

Figure 2. (A) qPCR was used to assess miR-17-5p expression in H460 cells transfected with miR-NC, miR-17-5p mimic or miR-17-5p inhibitor. (B) MTT assay and (C) flow cytometry were used to examine cell proliferation and apoptosis in each group. Non-transfected $\mathrm{H} 460$ cells were used as a control. ${ }^{* *} \mathrm{P}<0.01$ vs. control. qPCR, quantitative polymerase chain reaction; miR, microRNA; NC, negative control; FITC, fluorescein isothiocyanate; PI, propidium iodide.

(indicating cell apoptosis) and PI (indicating cell necrosis) and flow cytometry was performed. Annexin V-FITC positive/PI negative cells were at an early apoptotic stage, while Annexin V-FITC positive/PI positive cells were at late apoptotic/necrotic stage. As indicated in Fig. $2 \mathrm{C}$, the rate of apoptosis in the control group was $5.9 \%$, but increased to 9.4\% in miR-17-5p-overexpressing $\mathrm{H} 460$ cells, indicating that miR-17-5p induces H460 cell apoptosis. On the contrary, the apoptosis rate in $\mathrm{H} 460$ cells transfected with miR-17-5p inhibitor was $4.8 \%$, indicating that knockdown of miR-17-5p inhibits $\mathrm{H} 460$ cell apoptosis (Fig. 2C). In addition, the apoptosis rate in the miR-NC-transfected $\mathrm{H} 460$ cells was $6 \%$, and did not differ significantly from that in the control group (Fig. 2C).

TGF $R$ R2 is a direct target of miR-17-5p in NSCLC H46O cells. The putative targets of miR-17-5p in NSCLC were studied further by conducting a bioinformatical analysis. It was predicted that TGF $\beta$ R 2 is a direct target gene of miR-17-5p (Fig. 3A) and that this target relationship is evolutionally conserved (Fig. 3B). To confirm this, the wild-type or mutant type of the miR-17-5p binding sequence in the 3'UTR of TGF $\beta$ R2 was subcloned downstream of the firefly luciferase reporter gene in a pGL3 vector, named as pGL3-TGF $\beta$ R2-3'UTR and pGL3-TGF $\beta$ R2-mut-3'UTR
(Fig. 3C and D), respectively. These vectors were were then co-transfected with miR-17-5p mimic or miR-NC into H460 cells. A luciferase reporter assay was further conducted $48 \mathrm{~h}$ following transfection. Relative luciferase activity in H460 cells co-transfected with pGL3-TGFßR2-3'UTR and miR-17-5p mimic was significantly reduced, compared with the control group, which was co-transfected with pGL3-TGFßR2-3'UTR and miR-NC ( $\mathrm{P}<0.01$; Fig. 3E). However, relative luciferase activity in H460 cells co-transfected with pGL3-TGF $\beta$ R2-mut-3'UTR and miR-17-5p mimic did not differ from that in the control group (Fig. 3E). There results indicate that $\mathrm{miR}-17-5 \mathrm{p}$ can directly bind to the 3'UTR of TGF $\beta$ R 2 mRNA.

The effect of miR-17-5p on TGF $\beta R 2$ expression at the transcriptional and translational levels was investigated further using RT-qPCR and western blot analysis. The results of the present study indicated that levels of TGF $\beta$ R2 were significantly reduced in miR-17-5p-overexpressing H460 cells $(\mathrm{P}<0.01)$ and significantly increased following knockdown of miR-17-5p $(\mathrm{P}<0.01)$, compared with the control group (Fig. 3F and $G$ ). However, the data indicated that levels of TGF $\beta$ R2 mRNA were unaffected by miR-17-5p expression (Fig. 3H). These data indicate that miR-17-5p negatively mediates the expression of TGF $\beta R 2$ at the post-transcriptional level by directly binding to the 3'UTR of TGF $\beta R 2$ mRNA. 
A

\begin{tabular}{|c|c|c|c|c|c|c|}
\hline & $\begin{array}{l}\text { Predicted consequential paring of target region (top) } \\
\text { and miRuA (botorn) }\end{array}$ & $\begin{array}{c}\text { Sile } \\
\text { type }\end{array}$ & $\begin{array}{l}\text { Contexte- } \\
\text { score }\end{array}$ & $\begin{array}{l}\text { Contextru score } \\
\text { parcentile }\end{array}$ & $\begin{array}{c}\text { Weighted } \\
\text { contexte+score }\end{array}$ & $\begin{array}{ll}\begin{array}{c}\text { Conserved branch } \\
\text { lenght }\end{array} & \text { PCr } \\
\end{array}$ \\
\hline $\begin{array}{l}\text { Position 268-275 of TGFBR2 } 3 \text { UTR } \\
\text { hao-miR-17-5p }\end{array}$ & 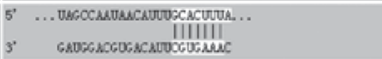 & 8mer & -0.47 & 99 & 0.47 & 10.992 \\
\hline
\end{tabular}

B

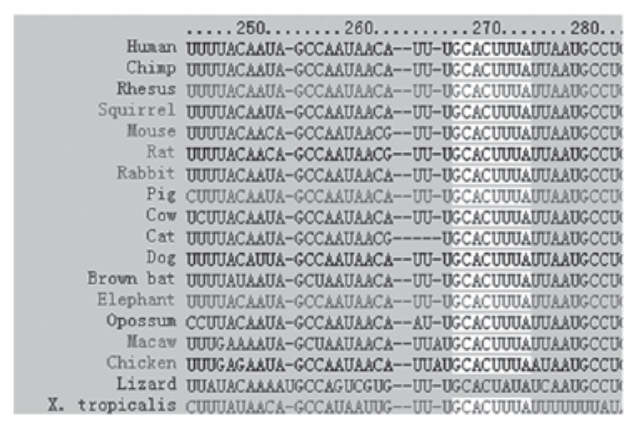

$\mathrm{E}$

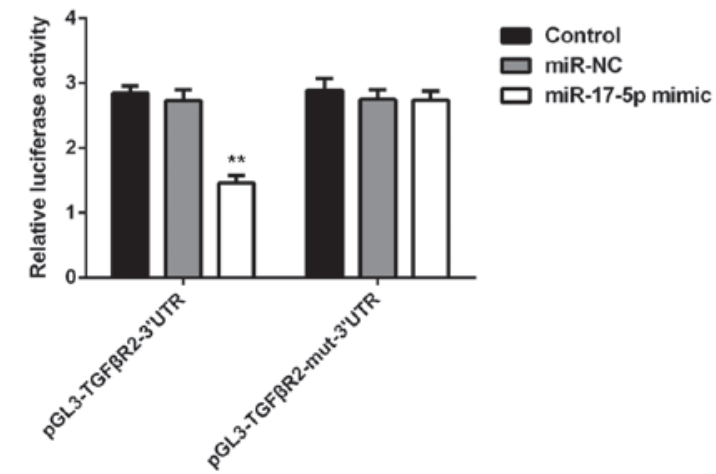

G

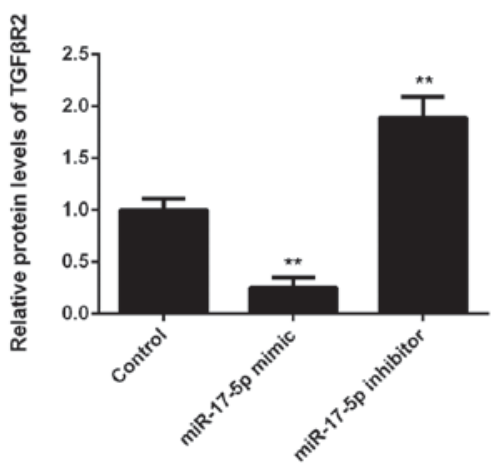

$\mathrm{C}$

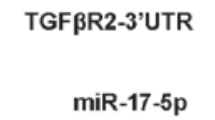

TGF $\beta$ R2-mut 3'UTR
5'....AUUUGCACUUUA....-3'

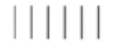

3'-...CAUUCGUGAAAC...-5'

| || |

5'-...AUUUGCACGGGA...-3'

D

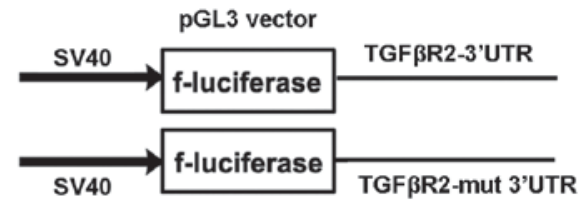

$\mathrm{F}$

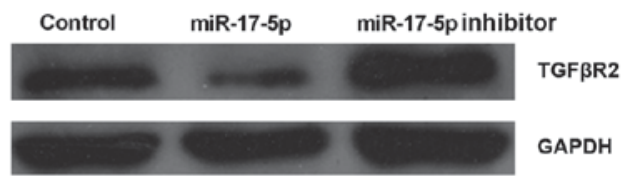

$\mathrm{H}$

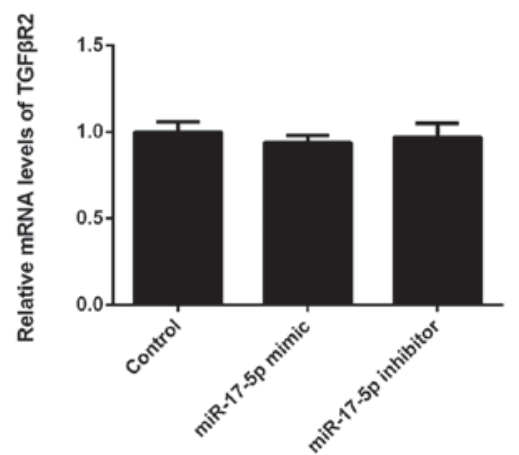

Figure 3. (A and B) Targetscan software indicated that TGF $\beta R 2$ is a direct target gene of miR-17-5p and their target relationship is evolutionally conserved. (C and D) The wild-type or mutant type of miR-17-5p binding sequence in the 3'UTR of TGF $\beta$ R2 were subcloned downstream of the firefly luciferase reporter gene in pGL3 vector, named as pGL3-TGF3R2-3'UTR or pGL3-TGF3R2-mut-3'UTR, respectively. (E) Relative luciferase activity in H460 cells co-transfected with pGL3-TGFßR2-3'UTR and miR-17-5p mimic was significantly reduced, compared with that in the control group, which was co-transfected with pGL3-TGFßR2-3'UTR and miR-NC. However, relative luciferase activity in H460 cells co-transfected with pGL3-TGF/R2-mut-3'UTR and miR-17-5p mimic showed no difference with the control group. ${ }^{* *} \mathrm{P}<0.01$ vs. control. ( $\mathrm{F}$ and $\left.\mathrm{G}\right)$ Western blot analysis and $(\mathrm{H}) \mathrm{RT}$-qPCR were used to examine levels of TGF $\beta$ R2 protein and mRNA, respectively, in H460 cells transfected with miR-17-5p mimic or inhibitor. Non-transfected H460 cells were used as control. ${ }^{* *} \mathrm{P}<0.01$ vs. control. Mut, mutant; TGF $\beta R 2$, transforming growth factor $\beta$ receptor 2; NSCLC, non-small cell lung cancer; UTR, untranslated region; NC, negative control; miR, microRNA; negative control; RT-qPCR, reverse transcription-quantitative polymerase chain reaction; GAPDH, glyceraldehyde 3-phosphate dehydrogenase.

TGF $\beta R 2$ is upregulated in NSCLC and involved in miR-17-5p-mediated $H 460$ cell proliferation and apoptosis. Levels of TGF $\beta$ R 2 mRNA were assessed in human NSCLC tissues and cell lines. The results of the present study indicated that TGF $\beta R 2$ was significantly upregulated in NSCLC tissues compared with non-tumorous lung tissues $(\mathrm{P}<0.01$; Fig. 4A). Additionally, levels of TGF $\beta \mathrm{R} 2 \mathrm{mRNA}$ were significantly higher in the T2-4 stage NSCLC tissues, compared with those in non-tumorous lung or T1 stage NSCLC tissues $(\mathrm{P}<0.01)$, suggesting that low miR-17-5p levels are associated with an advanced pathological stage of NSCLC (Fig. 4B). Accordingly, the expression profile of TGF $\beta R 2$ was in contrast with that of miR-17-5p in NSCLC tissue. It was further found that the TGF $\beta R 2$ mRNA levels 
A

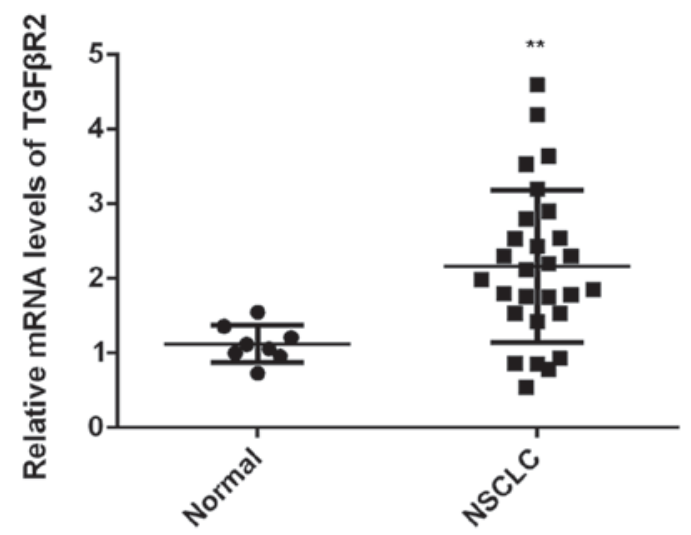

B

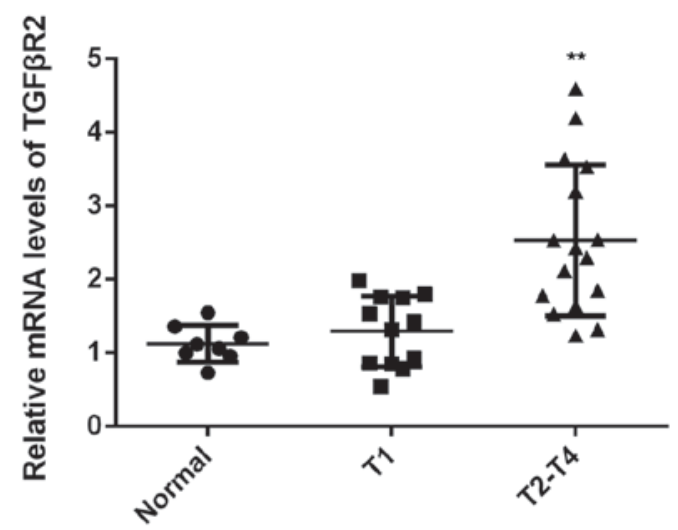

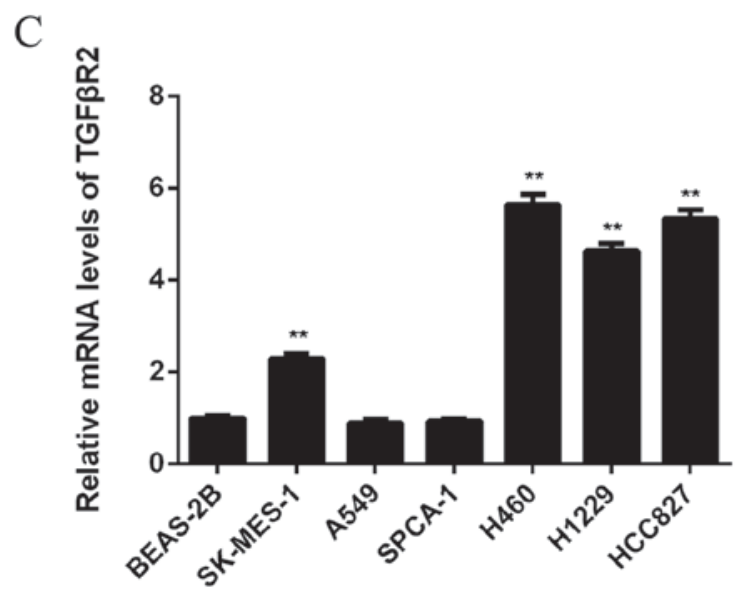

Figure 4. (A) RT-qPCR measured TGFßR2 mRNA levels in normal lung $(\mathrm{n}=7)$ and NSCLC $(\mathrm{n}=28)$ tissues. ${ }^{* *} \mathrm{P}<0.01$ vs. normal. (B) Lower mRNA levels of TGF $\beta R 2$ were associated with higher pathological stage (T2-T4) of NSCLC. ${ }^{* * *} \mathrm{P}<0.01 \mathrm{vs.} \mathrm{T1.} \mathrm{(C)} \mathrm{RT-qPCR} \mathrm{assessed} \mathrm{levels} \mathrm{of} \mathrm{TGF \beta R2} \mathrm{mRNA} \mathrm{in} \mathrm{the}$ human NSCLC cell lines SK-MES-1, A549, SPCA-1, H460, H1229 and HCC827, and the non-tumorous human bronchial epithelium cell line BEAS-2B. ${ }^{* *} \mathrm{P}<0.01$ vs. BEAS-2B. TGF $\beta$ R2, transforming growth factor $\beta$ receptor 2; NSCLC, non-small cell lung cancer; RT-qPCR, reverse transcription-quantitative polymerase chain reaction.

were also significantly increased in certain NSCLC cell lines including SK-MES-1, H1229, H460 and HCC827, compared with normal bronchial epithelium BEAS-2B cells $(\mathrm{P}<0.01$; Fig. 4C).

To further investigate whether TGFßR2 is involved in miR-17-5p-mediated NSCLC cell proliferation and apoptosis, TGF $\beta R 2$-specific siRNA was used to knockdown TGF $\beta$ R2 expression in H460 cells. Following transfection with TGF $\beta$ R2 siRNA, levels of TGF $\beta$ R 2 mRNA and protein were significantly downregulated $(\mathrm{P}<0.01)$ compared with the control siRNA-transfected $\mathrm{H} 460$ cells (Fig. 5A-C). An MTT assay was conducted to assess cell proliferation and the data indicated that TGF $\beta$ R2 knockdown led to a significant decrease in cell proliferation compared with control siRNA-transfected H460 cells $(\mathrm{P}<0.01$; Fig. 5D). Subsequently, the cell apoptotic rate was determined by flow cytometry. Rates of apoptosis in TGF $\beta R 2$ siRNA-transfected cells were significantly higher than in control siRNA-transfected cells $(\mathrm{P}<0.01)$, indicating that inhibition of TGF $\beta$ R2 enhanced apoptosis in H460 cells (Fig. 3E). Altogether, these data indicated that TGF $\beta$ R2 knockdown showed similar effects to miR-17-5p overexpression on $\mathrm{H} 460$ cell proliferation and apoptosis, and suggests that TGF $\beta R 2$ is involved in miR-17-5p-mediated H460 cell proliferation and apoptosis.

\section{Discussion}

The underlying mechanism of miRs in the development and progression of NSCLC remains largely unclear. In the present study, it was demonstrated that miR-17-5p is significantly downregulated in NSCLC tissues and cell lines, and lower miR-17-5p expression is associated with a higher pathological stage in NSCLC patients. Data from in vitro assays indicated that miR-17-5p inhibited proliferation and induced apoptosis of NSCLC H460 cells, possibly by directly inhibiting TGF $\beta$ R2, which was significantly upregulated in NSCLC tissues and cell lines.

As a member of the miR-17-92 family, it has been determined that miR-17-5p is involved in common human cancers, including hepatocellular carcinoma (23), gastric cancer (24), breast cancer (25), pancreatic cancer (26), glioblastoma (27), prostate cancer (28), cervical cancer (29), ovarian cancer (30), colon cancer (31) and lung cancer (32). Furthermore, it has been demonstrated that miR-17-5p can act as either an oncogene or a tumor suppressor $(23,25)$. For instance, it suppresses the proliferation of breast cancer cells by targeting AIB1 (33) but promotes their migration and invasion by targeting HBP1 (25). In the present study, it was shown that miR-17-5p, downregulated in NSCLC, was associated with the malignant 
A

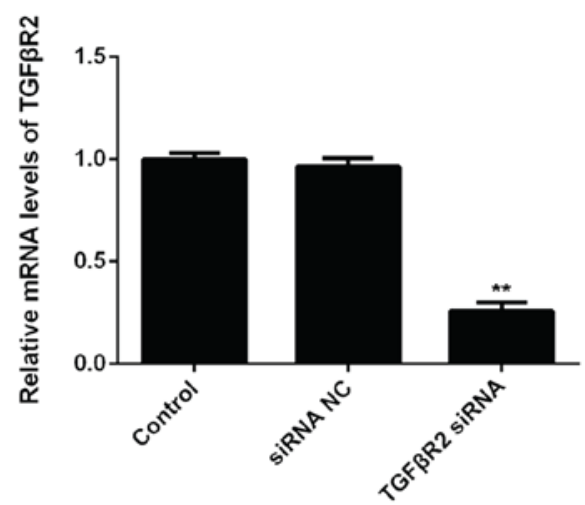

$\mathrm{C}$

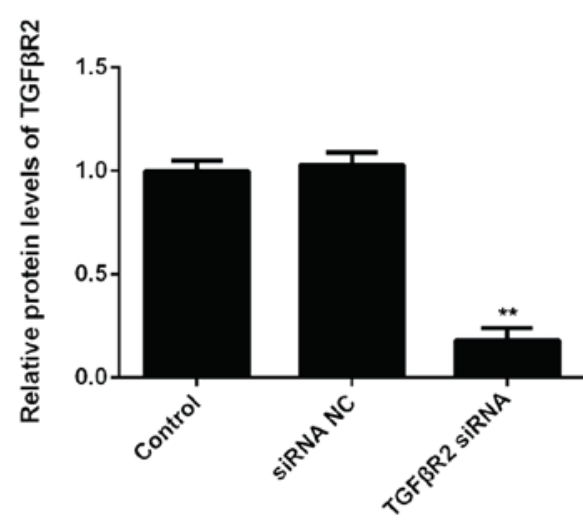

B

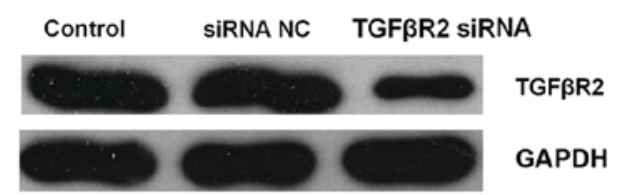

$\mathrm{D}$

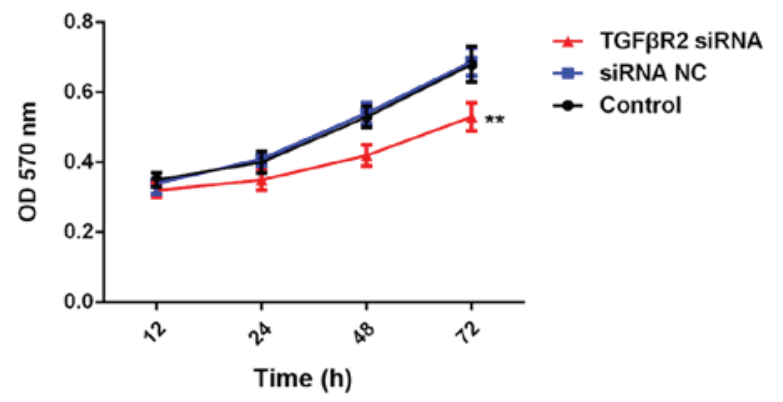

$\mathrm{E}$

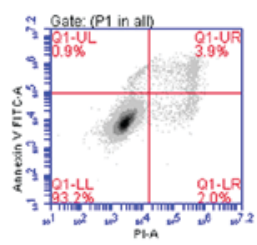

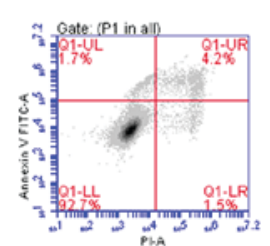

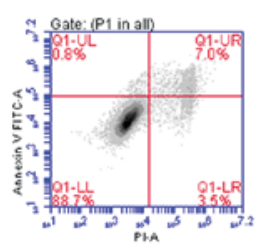

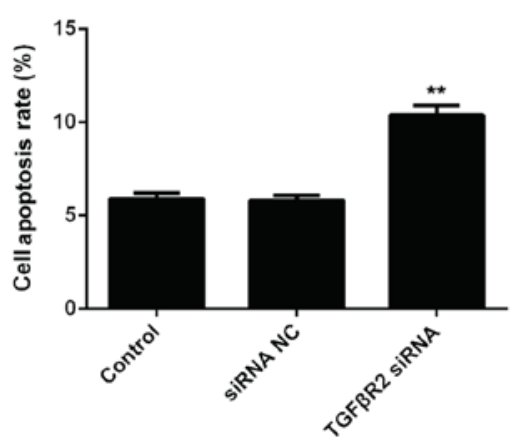

Figure 5. (A) RT-qPCR and (B) western blotting were conducted to measure levels of TGFßR2 mRNA and protein in H460 cells transfected with siRNA NC or TGFßR2 siRNA, respectively. (C) Relative protein expression levels were determined by densitometric analysis. (D) MTT assay and (E) flow cytometry were performed to examine cell proliferation and apoptosis in each group. Non-transfected $\mathrm{H} 460$ cells were used as a control. ${ }^{* * *} \mathrm{P}<0.01$ vs. control. RT-qPCR, reverse transcription-quantitative polymerase chain reaction; TGF $\beta$ R2, transforming growth factor $\beta$ receptor 2; siRNA, small interfering RNA; FITC, fluorescein isothiocyanate; $\mathrm{NC}$, negative control.

progression of NSCLC and inhibited NSCLC cell proliferation while inducing cell apoptosis. Previous studies have focused on the role of miR-17-5p in the chemoresistance and metastasis of NSCLC $(16,20)$. Therefore, the present study may have expanded understanding regarding the role of miR-17-5-p in NSCLC.

miRs function primarily by directly inhibiting the expression of their target genes, therefore the potential targets of miR-17-5p in NSCLC were investigated in the current study. Bioinformatical prediction and the results of the luciferase reporter assay revealed that TGF $\beta \mathrm{R} 2$ was a direct target gene of miR-17-5p. Furthermore, the results of the current study demonstrated that miR-17-5p downregulated the expression of TGF $\beta$ R 2 protein but did not alter the expression of TGF $\beta$ R2 mRNA in H460 cells. Recently, another study also reported that miR-17, 20a, 20b directly targeted TGF $\beta R 2$, reversing cisplatin resistance and suppressing migration by inhibiting epithelial-to-mesenchymal transition in A549/DDP cells (20). Han et al (19) analyzed the expression of TGF $\beta$ R2 in 308 NSCLC tissues, 42 of which were paired with adjacent non-tumorous tissues. It was determined that TGF $\beta \mathrm{R} 2$ was upregulated in NSCLC compared with normal tissues, and high expression of TGF $\beta R 2$ was significantly correlated with poor tumor differentiation, invasion of lung membrane and chemoresistance, as well as poor prognosis in patients that had undergone chemotherapy (19). Therefore, TGF $\beta$ R 2 appears to be a promising therapeutic target for NSCLC.

As overexpression of miR-17-5p suppressed proliferation, induced apoptosis and inhibited the expression of TGF $\beta R 2$ protein in H460 cells, it was speculated that TGF $\beta$ R 2 may be involved in miR-17-5p-mediated effects in $\mathrm{H} 460$ cells. Thus, TGF $3 R 2$-specific siRNA was used to knockdown expression 
of TGF $\beta R 2$ and mimic the effect of miR-17-5p overexpression in the present study. The results showed that downregulation of TGF $\beta$ R2 inhibited proliferation while triggering apoptosis in $\mathrm{H} 460$ cells. These observations suggest that TGF $\beta \mathrm{R} 2$ is involved in miR-17-5p-mediated $\mathrm{H} 460$ cell proliferation and apoptosis. In addition, it was determined that TGF $\beta R 2$ was upregulated in NSCLC tissues and cell lines, and that there was an association between high levels of TGF $\beta$ R2 and the malignant progression of NSCLC. Therefore, it is suggested that the upregulation of TGF $\beta \mathrm{R} 2$ may due to the downregulation of miR-17-5p in NSCLC.

In summary, the present study indicated that miR-17-5-p serves a regulatory role in the malignant progression of NSCLC and suggests that it may be a promising therapeutic target to treat NSCLC.

\section{References}

1. Siegel RL, Miller KD and Jemal A: Cancer statistics, 2015. CA Cancer J Clin 65: 5-29, 2015.

2. Jemal A, Bray F, Center MM, Ferlay J, Ward E and Forman D: Global cancer statistics. CA Cancer J Clin 61: 69-90, 2011.

3. Torre LA, Bray F, Siegel RL, Ferlay J, Lortet-Tieulent J and Jemal A: Global cancer statistics, 2012. CA Cancer J Clin 65 87-108, 2015.

4. Rottiers V and Näär AM: MicroRNAs in metabolism and metabolic disorders. Nat Rev Mol Cell Biol 13: 239-250, 2012.

5. Treiber T, Treiber N and Meister G: Regulation of microRNA biogenesis and function. Thromb Haemost 107: 605-610, 2012.

6. Su Z, Yang Z, Xu Y, Chen Y and Yu Q: MicroRNAs in apoptosis, autophagy and necroptosis. Oncotarget 6: 8474-8490, 2015.

7. Zhu W, He J, Chen D, Zhang B, Xu L, Ma H, Liu X, Zhang Y and Le H: Expression of miR-29c, miR-93, and miR-429 as potential biomarkers for detection of early stage non-small lung cancer. PLoS One 9: e87780, 2014.

8. Zhao JJ, Yang J, Lin J, Yao N, Zhu Y, Zheng J, Xu J, Cheng JQ, Lin JY and Ma X: Identification of miRNAs associated with tumorigenesis of retinoblastoma by miRNA microarray analysis. Childs Nerv Syst 25: 13-20, 2009.

9. Zhu J, Zheng Z, Wang J, Sun J, Wang P, Cheng X, Fu L, Zhang L, Wang $Z$ and Li Z: Different miRNA expression profiles between human breast cancer tumors and serum. Front Genet 5: 149, 2014

10. Ye JJ and Cao J: MicroRNAs in colorectal cancer as markers and targets: Recent advances. World J Gastroenterol 20: 4288-4299, 2014.

11. Li X, Yang W, Lou L, Chen Y, Wu S and Ding G: microRNA: A promising diagnostic biomarker and therapeutic target for hepatocellular carcinoma. Dig Dis Sci 59: 1099-1107, 2014.

12. Dal Bo M, Bomben R, Hernández L and Gattei V: The MYC/miR-17-92 axis in lymphoproliferative disorders: A common pathway with therapeutic potential. Oncotarget 6: 19381-19392, 2015.

13. Rogers LK, Robbins M, Dakhlallah D, Yang Z,Lee LJ, Mikhail M, Nuovo G, Pryhuber GS, McGwin G, Marsh CB and Tipple TE: Attenuation of miR-17 92 Cluster in Bronchopulmonary Dysplasia. Ann Am Thorac Soc 12: 1506-1513, 2015.

14. Ebi H, Sato T, Sugito N, Hosono Y, Yatabe Y, Matsuyama Y, Yamaguchi T, Osada H, Suzuki $M$ and Takahashi T: Counterbalance between RB inactivation and miR-17-92 overexpression in reactive oxygen species and DNA damage induction in lung cancers. Oncogene 28: 3371-3379, 2009.

15. Heegaard NH, Schetter AJ, Welsh JA, Yoneda M, Bowman ED and Harris CC: Circulating micro-RNA expression profiles in early stage nonsmall cell lung cancer. Int J Cancer 130: 1378-1386, 2012.
16. Chatterjee A, Chattopadhyay D and Chakrabarti G: miR-17-5p downregulation contributes to paclitaxel resistance of lung cancer cells through altering beclin1 expression. PLoS One 9: e95716, 2014.

17. Lyu X, Fang W, Cai L, Zheng H, Ye Y, Zhang L, Li J, Peng H, Cho WC, Wang E, et al: TGFbetaR2 is a major target of miR-93 in nasopharyngeal carcinoma aggressiveness. Mol Cancer 13: 51, 2014.

18. Huang SS and Huang JS: TGF-beta control of cell proliferation. J Cell Biochem 96: 447-462, 2005.

19. Han Y, Jia C, Cong X, Yu F, Cai H, Fang S, Cai L, Yang H, Sun Y, Li D, et al: Increased expression of TGFbetaR2 is associated with the clinical outcome of non-small cell lung cancer patients treated with chemotherapy. PLoS One 10: e0134682, 2015.

20. Jiang Z, Yin J, Fu W, Mo Y, Pan Y, Dai L, Huang H, Li S and Zhao J: MiRNA 17 family regulates cisplatin-resistant and metastasis by targeting TGFbetaR2 in NSCLC. PLoS One 9: e94639, 2014

21. Ettinger DS and Kris MG; NCCN Non-Small Cell Lung Cancer Practice Guidelines Panel: NCCN: Non-small cell lung cancer. Cancer Control 8 (6 Suppl 2): S22-S31, 2001.

22. Rao X, Huang X, Zhou Z and Lin X: An improvement of the $2^{\wedge}$ (-delta delta CT) method for quantitative real-time polymerase chain reaction data analysis. Biostat Bioinforma Biomath 3: 71-85, 2013.

23. Chen L, Jiang M, Yuan W and Tang H: miR-17-5p as a novel prognostic marker for hepatocellular carcinoma. J Invest Surg 25: 156-161, 2012.

24. Wang M, Gu H, Wang S, Qian H, Zhu W, Zhang L, Zhao C, Tao Y and Xu W: Circulating miR-17-5p and miR-20a: Molecular markers for gastric cancer. Mol Med Rep 5: 1514-1520, 2012.

25. Li H, Bian C, Liao L, Li J and Zhao RC: miR-17-5p promotes human breast cancer cell migration and invasion through suppression of HBP1. Breast Cancer Res Treat 126: 565-575, 2011.

26. Yu J, Ohuchida K, Mizumoto K, Fujita H, Nakata K and Tanaka M: MicroRNA miR-17-5p is overexpressed in pancreatic cancer, associated with a poor prognosis, and involved in cancer cell proliferation and invasion. Cancer Biol Ther 10: 748-757, 2010.

27. Li H and Yang BB: Stress response of glioblastoma cells mediated by miR-17-5p targeting PTEN and the passenger strand miR-17-3p targeting MDM2. Oncotarget 3: 1653-1668, 2012.

28. Yang X, Du WW, Li H, Liu F, Khorshidi A, Rutnam ZJ and Yang BB: Both mature miR-17-5p and passenger strand miR-17-3p target TIMP3 and induce prostate tumor growth and invasion. Nucleic Acids Res 41: 9688-9704, 2013.

29. Wei Q, Li YX, Liu M, Li X and Tang H: MiR-17-5p targets TP53INP1 and regulates cell proliferation and apoptosis of cervical cancer cells. IUBMB Life 64: 697-704, 2012.

30. Li L, He L, Zhao JL, Xiao J, Liu M, Li X and Tang H: MiR-17-5p up-regulates YES1 to modulate the cell cycle progression and apoptosis in ovarian cancer cell lines. J Cell Biochem 116: 1050-1059, 2015

31. Ma Y, Zhang P, Wang F, Zhang H, Yang Y, Shi C, Xia Y, Peng J, Liu W, Yang Z and Qin H: Elevated oncofoetal miR-17-5p expression regulates colorectal cancer progression by repressing its target gene P130. Nat Commun 3: 1291, 2012.

32. Chen Q, Si Q, Xiao S, Xie Q, Lin J, Wang C, Chen L, Chen Q and Wang L: Prognostic significance of serum miR-17-5p in lung cancer. Med Oncol 30: 353, 2013.

33. Hossain A, Kuo MT and Saunders GF: Mir-17-5p regulates breast cancer cell proliferation by inhibiting translation of AIB1 mRNA. Mol Cell Biol 26: 8191-8201, 2006. 